\title{
Importance Analysis of Urban Rail Transit Network Station Based on Passenger
}

\author{
Jun Jin ${ }^{1}$, Man Li ${ }^{1}$, Yanhui Wang ${ }^{1,2}$, Lingxi Zhu ${ }^{1,2}$, Liang Ping ${ }^{3}$, Bo Wang ${ }^{3}$, Ping Li ${ }^{3}$ \\ ${ }^{1}$ China School of Traffic \& Transportation, Beijing Jiaotong University, Beijing, China; ${ }^{2}$ State Key Laboratory of Rail Traffic Con- \\ trol \& Safety, Beijing Jiaotong University, Beijing, China; ${ }^{3}$ Rail Traffic Control Center, Beijing, China. \\ Email: jinjun12121012@163.com
}

Received May $14^{\text {th }}, 2013$; revised September $26^{\text {th }}, 2013$; accepted October $14^{\text {th }}, 2013$

Copyright (C) 2013 Jun Jin et al. This is an open access article distributed under the Creative Commons Attribution License, which permits unrestricted use, distribution, and reproduction in any medium, provided the original work is properly cited.

\begin{abstract}
Current urban rail transit has become a major mode of transportation, and passenger is an important factor of urban rail transport, so this article is based on passenger and the degree of the road network structure, calculating the point intensity of stations of urban rail transit, and then reaching a station importance by integrating many point intensities in a survey cycle time, and getting the station importance of urban rail transit network through concrete examples.
\end{abstract}

Keywords: Station Importance; Point Intensity; Passenger Urban Rail Transit Network

\section{Introduction}

Urban rail transit has been a rapid development in Chinese major cities, which is as the primary solution to solve urban congestion ills. After years of the development, it has gradually formed a network of urban rail transit operators in large cities such as Beijing, Shanghai, Guangzhou and others. Under the network operating, the station traffic, section traffic and so on, important operational indicators are used to reflect the operational status of rail, and provide an important basis for the organization and management. The station is the key of rail transit operations management, which is a key link in the process operators, and it protects the city rail premise security and stability operations, and how to efficiently run the station hierarchical management is the premise to guarantee urban rail security and stability operation.

However, there is only a qualitative analysis in traditional hierarchical management approach of the station and no dynamic variation is from the station's passenger quantitative grading. Therefore, this paper proposes a dynamic quantitative classification method based on the station passenger, providing the basis for the station operators under the conditions of the road network management and operation organizations.

\section{Basic Concepts}

\subsection{Road Network Model}

Drawing on the idea of the graph theory $[1,2]$, the road network model is defined by consisting of several nodes, the directed edge and the right, which is abstracted the physical network of the actual operation in urban rail transit. As is shown in Figure 1, and Figure 2 shows the actual operation road network of Beijing urban rail transit.

In Figure 1, $L_{1}, L_{2}, L_{i}, \cdots, L_{n}$ mean the line representing the spatial relationship of the section in the road network; the node $S_{i j}$ means the station $j$ in the corresponding $i$ line in the road network.

\subsection{Basic Concepts}

Introduced concept of the degree on the basis of the above model, the degree of the node $S_{i j}$ is the number of the edges associated with $S_{i j}$, denoted as $d\left(s_{i j}\right)$. The following is given based on the concept of the degree of a node definition [3]:

Node: a point $S_{i j}$, if $d\left(s_{i j}\right) \geq 1$, then the point $S_{i j}$ is the node.

Key nodes: a point $S_{i j}$, if $d\left(s_{i j}\right) \geq 3$, the point $S_{i j}$ is the transfer node. Here, it refers to the transfer station and the greater impact on the node Passenger Route Choice.

Point of strength: the station operational process safety important degree, which is not only related with the station node (station connecting edges), but the amount of inbound and outbound under the urban rail transit network diagram. 


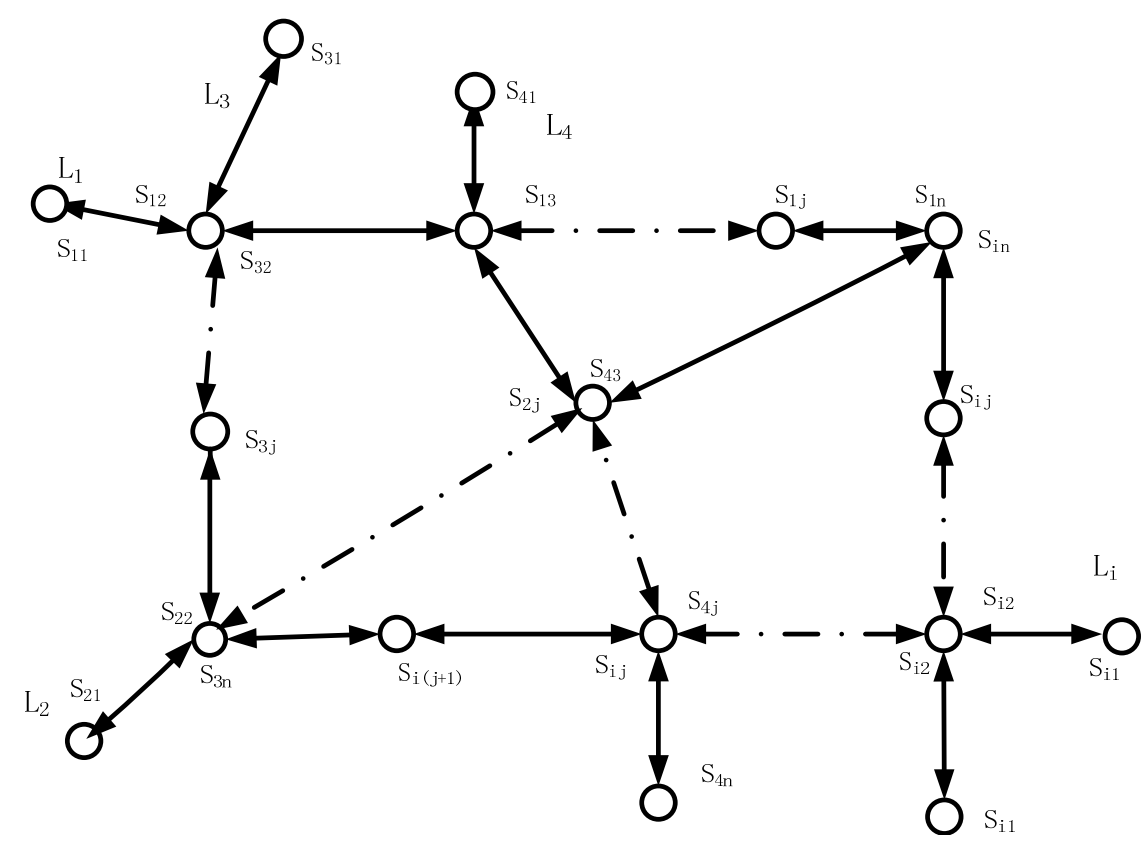

Figure 1. The urban rail transit network model.

\section{Station Important Degree Research}

The station importance refers to the influence extent of a station for the road network operational safety. The greater station importance indicates that the more important in the road network.

\subsection{The Points Strength Calculation}

According to the spatial and temporal characteristics of urban rail transit [4], the point strength of each station is different with the change of time and space [5], and reflects the dynamic changes in the station weight. When a security elements affecting the station security operations, the greater point intensity, the greater the impact on the whole line and road network [6]. The station $j$ point strength in the time period $t$ can be expressed as follows in the urban rail transit network model:

$$
k_{t}\left(s_{i j}\right)=d\left(s_{i j}\right) \cdot \frac{c_{t}^{\text {in }}\left(s_{i j}\right)+c_{t}^{\text {out }}\left(s_{i j}\right)+c_{t}^{\text {tc }}\left(s_{i j}\right)}{\sum_{j=1}^{m}\left(c_{t}^{\text {in }}\left(s_{i j}\right)+c_{t}^{\text {out }}\left(s_{i j}\right)+c_{t}^{\text {tc }}\left(s_{i j}\right)\right)}
$$

where: $d\left(s_{i j}\right)$ is the degree of the station $j ; c_{t}^{i n}\left(s_{i j}\right)$ is the input volume of the station $j ; c_{t}^{\text {out }}\left(s_{i j}\right)$ is the output volume of the station $j ; c_{t}^{t c}\left(s_{i j}\right)$ is the transfer volume of the station $j$.

\subsection{The Station Importance Calculation}

Due to the point intensity changes with time and space, the station point strength research in a statistical cycle of the road network. The station importance is based on the station point strength with time and space, which specific is as follows:

Assuming that there are $m$ stations in the road network, and the statistical period $T$ is divided into $n$ time periods for the station $j$ respectively $t_{1}, t_{2}, t_{3}, \cdots, t_{n}$, corresponding to the point of strength are

$$
k_{j t_{1}}, k_{j t_{2}}, k_{j t_{3}}, \cdots, k_{j t_{n}},
$$

then, the $m$ point intensity matrix in a statistical cycle is shown:

$$
\left(\begin{array}{ccccc}
k_{1 t_{1}} & k_{1 t_{2}} & k_{1 t_{3}} & \cdots & k_{1 t_{n}} \\
k_{2 t_{1}} & k_{2 t_{2}} & k_{2 t_{3}} & \cdots & k_{2 t_{n}} \\
\vdots & \vdots & \vdots & \ddots & \vdots \\
k_{m t_{1}} & k_{m t_{2}} & k_{m t_{3}} & \cdots & k_{m t_{n}}
\end{array}\right)
$$

If the station in and out passenger are

$$
c_{t_{1}}, c_{t_{2}}, c_{t_{3}}, \cdots, c_{t_{n}}
$$

during the statistical cycle of $n$ periods, the total traffic is

$$
C=\sum_{x=1}^{n} c_{t_{x}},
$$

and the weight coefficient matrix of the station in and out traffic is

$$
\left(\begin{array}{lllll}
\frac{C_{t_{1}}}{C} & \frac{C_{t_{2}}}{C} & \frac{C_{t_{3}}}{C} & \cdots & \frac{C_{t_{n}}}{C}
\end{array}\right) .
$$

If the $m$ stations importance degree

$$
Z_{1}, Z_{2}, Z_{3}, Z_{4}, \cdots, Z_{m},
$$

then 


$$
\left(\begin{array}{c}
Z_{1} \\
Z_{2} \\
Z_{3} \\
\vdots \\
Z_{m}
\end{array}\right)=\left(\begin{array}{ccccc}
k_{1 t_{1}} & k_{1 t_{2}} & k_{1 t_{3}} & \cdots & k_{1 t_{n}} \\
k_{2 t_{1}} & k_{2 t_{2}} & k_{2 t_{3}} & \cdots & k_{2 t_{n}} \\
\vdots & \vdots & \vdots & \ddots & \vdots \\
k_{m t_{1}} & k_{m t_{2}} & k_{m t_{3}} & \cdots & k_{m t_{n}}
\end{array}\right)\left(\begin{array}{c}
\frac{c_{t_{1}}}{C} \\
\frac{c_{t_{2}}}{C} \\
\vdots \\
c_{t_{n}} \\
C
\end{array}\right)
$$

So the important degree of the station $j$ on the spatial and temporal distribution

$$
Z_{i}=\sum_{x=1}^{n} k_{j t_{j}} \frac{C_{t_{x}}}{C}(1 \leq j \leq m)
$$

\section{Station Important Calculation Example Application}

\subsection{Road Network Model}

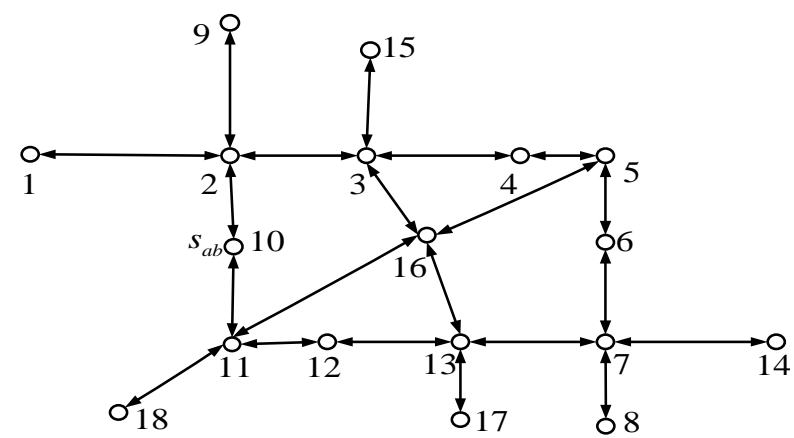

Figure 2. The road network model.

\subsection{The Calculation of the Points Strength and the Importance Degree}

Assumed that the subway operators time from 6:00 am to 10:00 pm in urban rail network, and the statistical cycle is 16 hours, which is divided into 6:00 - 8:00, 8:00 10:00, 10:00 - 12:00, 12:00 - 14:00, 14:00 - 16:00, 16:00 - 18:00, 18:00 - 20:00, 20:00 - 22:00

$$
\left(t_{1}, t_{2}, t_{3}, t_{4}, t_{5}, t_{6}, t_{7}, t_{8}\right) \text {. }
$$

The following is Tables 1-3 show the 18 station traffic of the road network in the statistical cycle.

The importance degree of the station can be calculated through the above data into the formula (1), (2) and (3) (see the formula on the bottom of the page).

From Figure 3, the degree of importance of the station 2 , station 3 , station 5 , station 7 and station 11 , station 13 and station 16 is significantly larger than the other stations, and these stations is the bigger traffic, the larger node degree and the transfer station, which fits the important degree of formula and method of the above calculation station.

\section{Conclusion}

This paper provided the point definition and calculation of the intensity of the urban rail transit station based on the node degree in passenger traffic and road network model, and gave the concept and the specific calculation method of the station importance degree according to

$\left(\begin{array}{l}Z_{1} \\ Z_{2} \\ Z_{3} \\ Z_{4} \\ Z_{5} \\ Z_{6} \\ Z_{7} \\ Z_{8} \\ Z_{9} \\ Z_{10} \\ Z_{11} \\ Z_{12} \\ Z_{13} \\ Z_{14} \\ Z_{15} \\ Z_{16} \\ Z_{17} \\ Z_{18}\end{array}\right)=\left(\begin{array}{llllllll}0.02 & 0.02 & 0.01 & 0.01 & 0.02 & 0.02 & 0.02 & 0.01 \\ 0.49 & 0.42 & 0.28 & 0.35 & 0.37 & 0.46 & 0.49 & 0.39 \\ 0.33 & 0.38 & 0.47 & 0.27 & 0.29 & 0.33 & 0.35 & 0.32 \\ 0.06 & 0.07 & 0.05 & 0.05 & 0.08 & 0.07 & 0.09 & 0.05 \\ 0.19 & 0.18 & 0.17 & 0.18 & 0.19 & 0.21 & 0.23 & 0.13 \\ 0.07 & 0.08 & 0.10 & 0.13 & 0.09 & 0.07 & 0.08 & 0.10 \\ 0.59 & 0.34 & 0.39 & 0.48 & 0.38 & 0.62 & 0.36 & 0.40 \\ 0.02 & 0.03 & 0.02 & 0.02 & 0.03 & 0.02 & 0.03 & 0.02 \\ 0.03 & 0.02 & 0.02 & 0.03 & 0.03 & 0.03 & 0.03 & 0.04 \\ 0.07 & 0.07 & 0.05 & 0.09 & 0.08 & 0.07 & 0.09 & 0.10 \\ 0.46 & 0.45 & 0.46 & 0.38 & 0.43 & 0.41 & 0.43 & 0.24 \\ 0.04 & 0.02 & 0.03 & 0.03 & 0.03 & 0.04 & 0.03 & 0.05 \\ 0.28 & 0.39 & 0.50 & 0.37 & 0.39 & 0.31 & 0.23 & 0.37 \\ 0.02 & 0.02 & 0.02 & 0.02 & 0.02 & 0.02 & 0.03 & 0.03 \\ 0.03 & 0.02 & 0.02 & 0.02 & 0.02 & 0.03 & 0.03 & 0.02 \\ 0.53 & 0.70 & 0.64 & 0.66 & 0.61 & 0.44 & 0.47 & 0.68 \\ 0.02 & 0.03 & 0.03 & 0.03 & 0.04 & 0.03 & 0.05 & 0.04 \\ 0.02 & 0.02 & 0.02 & 0.03 & 0.01 & 0.03 & 0.02 & 0.04\end{array}\right)\left(\begin{array}{l}0.17 \\ 0.15 \\ 0.09 \\ 0.07 \\ 0.15 \\ 0.18 \\ 0.12 \\ 0.07\end{array}\right)=\left(\begin{array}{l}0.02 \\ 0.42 \\ 0.34 \\ 0.07 \\ 0.19 \\ 0.08 \\ 0.46 \\ 0.02 \\ 0.03 \\ 0.08 \\ 0.42 \\ 0.03 \\ 0.34 \\ 0.02 \\ 0.02 \\ 0.57 \\ 0.03 \\ 0.02\end{array}\right)$


Table 1. The in and out of the station traffic.

\begin{tabular}{|c|c|c|c|c|c|c|c|c|}
\hline Station & $6: 00-8: 00$ & $8: 00-10: 00$ & $10: 00-12: 00$ & $12: 00-14: 00$ & $14: 00-16: 00$ & $16: 00-18: 00$ & $18: 00$ - 20:00 & $20: 00-22: 00$ \\
\hline 1 & 206 & 146 & 56 & 34 & 134 & 226 & 114 & 43 \\
\hline 2 & 653 & 489 & 234 & 224 & 421 & 623 & 456 & 214 \\
\hline 3 & 450 & 447 & 357 & 168 & 345 & 453 & 333 & 174 \\
\hline 4 & 312 & 297 & 138 & 97 & 313 & 342 & 298 & 89 \\
\hline 5 & 356 & 302 & 198 & 112 & 298 & 396 & 302 & 95 \\
\hline 6 & 321 & 338 & 256 & 254 & 345 & 334 & 278 & 178 \\
\hline 7 & 773 & 403 & 302 & 257 & 436 & 873 & 339 & 231 \\
\hline 8 & 154 & 214 & 104 & 78 & 225 & 164 & 198 & 66 \\
\hline 9 & 246 & 202 & 89 & 113 & 245 & 266 & 224 & 132 \\
\hline 10 & 367 & 298 & 135 & 164 & 334 & 361 & 287 & 177 \\
\hline 11 & 608 & 517 & 347 & 226 & 487 & 588 & 398 & 118 \\
\hline 12 & 196 & 78 & 67 & 59 & 135 & 213 & 99 & 77 \\
\hline 13 & 394 & 462 & 325 & 224 & 441 & 402 & 227 & 195 \\
\hline 14 & 148 & 134 & 123 & 89 & 188 & 168 & 168 & 115 \\
\hline 15 & 252 & 189 & 97 & 74 & 176 & 257 & 176 & 63 \\
\hline 16 & 704 & 786 & 467 & 371 & 665 & 604 & 442 & 337 \\
\hline 17 & 212 & 228 & 175 & 115 & 331 & 262 & 298 & 147 \\
\hline 18 & 203 & 135 & 88 & 126 & 114 & 253 & 132 & 121 \\
\hline Total & 6555 & 5665 & 3558 & 2785 & 5633 & 6785 & 4769 & 2572 \\
\hline
\end{tabular}

Table 2. The transfer traffic.

\begin{tabular}{ccccccccc}
\hline Station & $6: 00-8: 00$ & $8: 00-10: 00$ & $10: 00-12: 00$ & $12: 00-14: 00$ & $14: 00-16: 00$ & $16: 00-18: 00$ & $18: 00-20: 00$ & $20: 00-22: 00$ \\
\hline 2 & 553 & 389 & 134 & 114 & 321 & 523 & 356 & 123 \\
3 & 350 & 347 & 257 & 89 & 245 & 354 & 243 & 98 \\
5 & 256 & 202 & 102 & 113 & 211 & 296 & 200 & 56 \\
7 & 673 & 305 & 204 & 208 & 334 & 665 & 256 & 114 \\
11 & 508 & 417 & 246 & 145 & 376 & 442 & 304 & 89 \\
13 & 294 & 362 & 326 & 134 & 346 & 365 & 145 & 118 \\
16 & 604 & 667 & 367 & 268 & 557 & 498 & 334 & 247 \\
Total & 3238 & 2689 & 1636 & 1071 & 2390 & 3143 & 1838 & 845 \\
\hline
\end{tabular}

Table 3. The degree of the station.

\begin{tabular}{ccccccccccccccccccc}
\hline Station & 1 & 2 & 3 & 4 & 5 & 6 & 7 & 8 & 9 & 10 & 11 & 12 & 13 & 14 & 15 & 16 & 17 & 18 \\
\hline The Degree & 1 & 4 & 4 & 2 & 3 & 2 & 4 & 1 & 1 & 2 & 4 & 2 & 4 & 1 & 1 & 4 & 1 & 1 \\
\hline
\end{tabular}

The distribution of the station importance

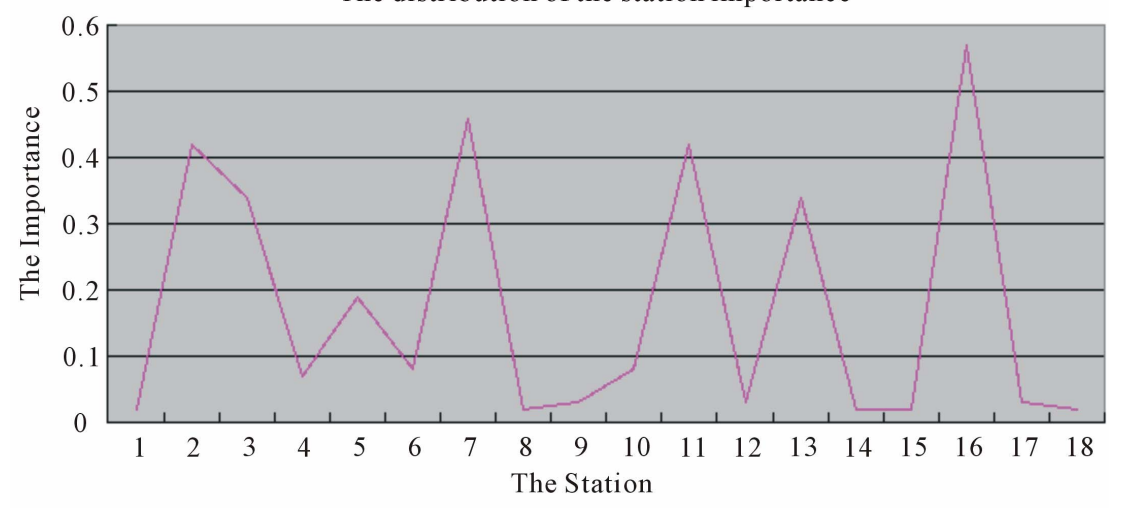

Figure 3. The distribution of the station importance. 
the characteristics of the spatial and temporal distribution. It embodied the abstract important degree and specific validation to support the management of the station.

\section{Acknowledgements}

This investigation is supported by National "Twelfth FiveYear” Plan for Science \& Technology Support-Urban Rail Transit Network Operations Security Key Technologies and System Development (2011BAG01B02).

\section{REFERENCES}

[1] J. N. Li and Q. L. Zhang, "Graphic Theory on Interval Stability of Networked Control System," Journal of Systems Engineering and Electronics, Vol. 19, No. 6, 2008, pp. 1185-1190.
http://dx.doi.org/10.1016/S1004-4132(08)60217-0

[2] X. N. Huang and Y. B. Zhu, "Nodal Analysis Based on Graph Theory,” Qinghai Normal University, No. 2, 2011, pp. 17-20.

[3] J. Xu and Z. Bao, "Neural Networks and Graph Theory," Science in China, Vol. 45, No. 1, 2002, pp. 1-23. http://dx.doi.org/10.1360/02ye9001

[4] M. Yuan, L. Deng and Y. Huang, "A Selection Study for Railway Transport and Transfer Node,” Modern Business Trade Industry, No. 1, 2010, pp. 23-24.

[5] C. Chen, H. X. Xue and Q. M. Zhang, "Importance Analysis Based on the Reliability Redundant Design and Supply Chain Members,” Technical Economics, Vol. 28, No. 3, 2009, pp. 113-118.

[6] J. H. Jia, L. H. Bao, J. X. Zhu, et al., "Important Degree Analysis of Regional Highway Network Layout Optimization,” Northeast Highway, Vol. 24, No. 2, 2001, pp. 4648. 